\title{
Anxiety and Depression Among Cancer Patients: Prevalence and Associated Factors at a Rwandan Referral Hospital
}

\author{
Marie Goretti Uwayezu*, Darius Gishoma ${ }^{1}$, Ruth $\mathrm{Sego}^{2}$, Madeleine Mukeshimana ${ }^{1}$, Anita Collins ${ }^{2}$ \\ ${ }^{1}$ School of Nursing and Midwifery, University of Rwanda, College of Medicine and Health Sciences, Kigali, Rwanda \\ ${ }^{2}$ Rory Meyer's College of Nursing, New York University, New York, US A
}

*Corresponding author: Marie Goretti Uwayezu. School of Nursing and Midwifery, University of Rwanda, College of Medicine and Health Sciences, Remera Campus, 11 KG 47, Kigali, Rwanda. Email: muwayezu5@gmail.com

\begin{abstract}
Background

Cancer patients frequently experience psychological problems related to reactions of cancer diagnosis, cancer type, treatment effects, recurrence, fear of end-of-life, survivorship, and financial burden. Psychological assessment has been integrated into cancer care in some countries, but there is limited knowledge about the practice in Rwanda.

Objective

To assess the prevalence and associated factors of anxiety and depression among patients with cancer attending a private referral hospital in Rwanda.

Methods

A descriptive cross-sectional study design was used with the Hospital Anxiety and Depression Scale (HADS) instrument to assess cancer patients. A probability systematic random sampling technique was used to recruit 96 patients. Data were analysed using descriptive statistics to determine the association of variables with anxiety and depression.

Results

The majority of cancer patients had depression (67.7\%) and anxiety (52.1\%). Anxiety was associated with employment status $(p=0.02)$, cancer stage $(p=0.02)$, weight loss $(p=0.00)$ and depression $(p=0.00)$. Depression was associated with cancer stage $(p=0.02)$, pain $(p=0.03)$, weight loss $(\mathrm{p}=0.03)$, cancer treatment $(\mathrm{p}=0.02)$ and anxiety $(\mathrm{p}=0.001)$.

Conclusion: Anxiety and depression were reported in over half of the study population indicating a need to create and integrate psycho-oncology into standard oncology care.
\end{abstract}

Rwanda J Med Health Sci 2019;2(2):118-125.

Keywords: Cancer, anxiety, depression, prevalence, associated factors

\section{Background}

Anxiety and depression are common complications of cancer often neglected.[1] Cancer is a feared diagnosis, and cancer patients demonstrate a higher tendency for psychological and emotional stress compared to the general population.[2] A recent clinical practice review reported that depression affects about $20 \%$, and anxiety about $10 \%$ of cancer patients, compared to $5 \%$ and $7 \%$ in the general population.[1]

A higher prevalence of anxiety and depressionis related to reactions to the cancer diagnosis, the cancer type, treatment and side effects, recurrence, fear of end-of-life care, and survivorship.[1,3,4] Although anxiety and depression are common, they are not well-recognised cancer complications, yet they cause a reduction in the quality of life and survival, treatment compliance, and increase cost.[1,5]
In 2012, the global prevalence of cancer cases was 14.1 million and was estimated to increase to 21.6 million by 2030 , which will significantly affect cancer care and the number of required health care providers.[1] The highest increase is expected to be in low-and-middleincome countries (LMIC), where non-communicable diseases (NCDs) are on the rise.[6] Cancer patients often feel that their emotional needs are not meet as much as their physical needs. [4-6] Though, according to the America Cancer Society, those experiencing anxiety and depression can nearly always be helped.[6]

Many countries have recently integrated psycho-oncology into cancer care using a multi-disciplinary approach, including psychological and lifestyle support.[1,6] Psycho-oncology is the psychological, social, behavioural, and ethical aspects of cancer care and focuses on the well being of the patient and family.[5-6] Many high- 
resource countries have integrated psychological and social support with the involvement of oncology nurses, social workers, psychologists and psychiatrists in order to prevent and manage psychosocial issues arising with cancer care.[7] Most low-resource countries have not yet established psychological support,[8] though, in Rwanda, the Butaro Cancer Center of Excellence offers mental and social support to improve the quality of life for their cancer patients. [9]

Risk factors of anxiety and depression among cancer patients are not well recognised and associated with a reduced quality of life and survival.[1] Anxiety disorders appear to be related to performance status, whereas depressive states are associated with age, pain, and performance status.[10] Women with cancer are more at risk for anxiety and depression,[11] especially those with breast and gynaecological cancers, or a history of anxiety and depression.[12] Cancer patients over age 40, Christian, and those who have not yet started cancer treatment are more at risk of anxiety,[12] or depression,[13] compared to post-surgical patients.[13] Type of cancer treatment is a significant factor for depression.[13] Other factors associated with anxiety and depression include the presence of cancer in the family, educational level, the severity of pain,[14] low socio-economic level,[15] and inadequate social support.[16]

In Rwanda, the Government and Non-Government Organizations (NGOs) have improved the medical management of cancer through awareness and screening programs,[17] but few have a psychological support component to the program. There is also limited research on the topic in Rwanda. This study was conducted to address the paucity of research related to the psychological conditions of cancer patients in Rwanda. The purpose of the study was to assess the prevalence of anxiety and depression, and its associated factors among cancer patients who attended an oncology unit at a referral hospital in Kigali.

\section{Methods}

\section{Design}

A descriptive cross-sectional study was conducted in the Oncology Department in one of Rwanda's four referral hospitals. Data were collected during weekdays from 3 April to 12 May 2017.

\section{Participants' recruitment}

Participants aged 18 years or older, with a cancer diagnosis at any stage, and on curative or palliative care, were included. Cancer survivors, or those with cancer and less than 18 years, were excluded. The sample frame consisted of patients scheduled for chemotherapy, prechemotherapy, laboratory investigation, or consultation during the scheduled data collection period. Using Cochran formula, a sample size of 96 was calculated using a confidence level of $95 \%$ and a significance level of 0.05 . The study used a systematic random sampling technique, an equiprobability method with a $\mathrm{K}=4$ (sampling interval) calculated by dividing the total population $(333)$ by the sample size $(n=96)$.

\section{Measures}

The questionnaire consisted of three sections that included sociodemographic information, cancer clinical characteristics and treatment, and the Hospital Anxiety and Depression Scale (HADS) anxiety scale. Zigmond and Snaith developed the HADS.[18] The HADS is a valid and reliable instrument, which was originally designed to assess psychiatric conditions (anxiety and depression) in general medical settings and not psychiatric clinics.[18] Zigmond and Snaith were careful to separate the emotional concepts from physical illness, and therefore the reliability score demonstrated it was related to psychological issues and not a biological illness.[19] Cronbach's alpha was 0.82.[19]

Section 1: Sociodemographic information and a history of mental disorder (7 items)

Section 2: Cancer clinical characteristics and treatment (11 items)

Section 3: The Hospital Anxiety and Depression Scale (HADS) anxiety scale (14 items)

The HADS instrument consists of alternating seven general anxiety items $(1,3,5,7,9,11,13)$ with seven depression items $(2,4,6,8,10,12,14)$. The HADS was scored on a four-point Likert scale ranging from zero to three. The first item on the general anxiety scale 'I feel tense or wound-up', offers the following responses: 'most of the time, ' 'very often', 'from time to time/ occasionally' and 'not at all' which are scored by 3, 2, 1 and 0 respectively. Depression was scored in the same manner, for example, item 2 is 'I still enjoy the things I used to enjoy', and the responses include: 'definitely as much', 'not quite so much, 'only a little' and 'hardly at all'. These responses also are scored by 0,1,2,3 respectively.[20] Responses to the items were based on how the participants have been feeling in the preceding week as recommended by the original author of the instrument.[18]

The item scores were added to give subscale scores from 0 to 21 . Higher scores indicate more depression and, or, anxiety. The total score would then be defined as one of four categories for both anxiety and depression: [21]

- No case (0-7) without clinical symptoms

- Mild (8-10) doubtful or suspicious cases of anxiety or depression

- Moderate (11-21) definite cases or symptomatic anxiety or depression

The final instrument was translated in Kinyarwanda the local language to reflect terms with the same meaning as the original scale items. Two clinical psychologists and two linguistic experts reviewed the translated version. A 
pilot test was conducted on nine cancer patients, who did not appear in the final sample, in order to test the feasibility of the instrument.

\section{Data collection}

The sample frame consisted of patients who attended a consultation, pre-chemotherapy laboratory exams, and chemotherapy. A list of codes of selected patients was given to the nurse of the oncology unit, and they advised the patients about the study and the presence of a study investigator. While waiting for their consultation and treatment, the investigator approached a patient based on the list above. The purpose of the study was explained, and the letter of information was given to the patients. Those who accepted to participate signed the consent form knowing that their information was anonymous, and they could withdraw from the study. The data collection tool was a self-reported questionnaire, but verbal or written assistance with a question was given when needed. The questionnaire took 10 to 15 minutes to complete.

\section{Data analysis}

The prevalence of anxiety and depression was estimated using frequencies. A Chi-square test was used to measure the association between social demographic variables and anxiety and depression prevalence, and medical and cancer-related variables among cancer patients. Data was entered and analysed by using SPSS (version 21).

\section{Ethical considerations}

The University of Rwanda, College of Medicine and Health Science, Institutional Review Board, and the ethics committee at the referral hospital approved the study. All patients signed a consent form before data collection.

\section{Results}

The study results indicated that the majority of participants were female $(58.3 \%)$, married $(73 \%)$, and with health insurance $(91.7 \%)$ (table 1$)$. The mean age was 52 years, with a range of $18-78$ years. The majority was not employed $(55.2 \%)$, as many were retired or experienced cancer-related disability. Nearly one third $(30.2 \%)$ had breast cancer, which was the most common type among study participants. The patients' records showed that half of the cancer patients $(49.4 \%)$ had stage three and four cancer, and most were accessing treatment $(93.8 \%)$ and receiving chemotherapy $(92.1 \%)$.
Table 1. Socio-Demographic Characteristics $(n=96)$

\begin{tabular}{ll}
\hline Variables & n (\%) \\
\hline Gender & \\
Male & $40(41.7)$ \\
Female & $56(58.3)$ \\
Age group & $11(11.5)$ \\
18-35 & $16(16.7)$ \\
$36-43$ & $43(44.8)$ \\
44-61 & $26(44.8)$ \\
62-89 & $5(5.2)$ \\
Martial status & $70(72.9)$ \\
Single & $1(1.0)$ \\
Married & $6(6.3)$ \\
Cohabiting & $14(14.6)$ \\
Separated & $84(87.5)$ \\
Widow & $4(4.2)$ \\
Living with & $8(8.3)$ \\
Family & $53(55.2)$ \\
Friend & $43(44.8)$ \\
Alone & $88(91.7)$ \\
Employment status & $8(8.3)$ \\
Eot employed & \\
Health insurance & \\
Yes & \\
\hline & \\
\hline & \\
\hline
\end{tabular}

The study results show that a quarter $(26 \%)$ of participants had mild anxiety, and another quarter $(26 \%)$ had symptomatic anxiety (table 2$)$. A third (32.3\%) of participants had mild depression, and a third (34.4\%) had symptomatic depression. The prevalence of anxiety and depression included all participants who have the score $\geq 8$ (mild and symptomatic cases); therefore, over half $(52.1 \%)$ had anxiety, and two-thirds $(67.7 \%)$ of the study population had depression.

\section{Significant association of anxiety and depression}

The data indicated that there were four significant statistical associations with anxiety and five with depression (table 3). For demographic characteristics, the results showed that anxiety was associated with employment status $(\mathrm{p}=0.02)$. Cancer and clinical characteristics associated with anxiety included cancer stage $(p=0.02)$, weight loss $(p=0.00)$, fatigue $(p=0.01)$ and depression $(\mathrm{p}=0.02)$. There was also a significant statistical association between depression and weight loss $(p=0.02)$, pain $(p=0.03)$, fatigue $(p=0.02)$, cancer treatment $(\mathrm{p}=0.04)$ and anxiety $(\mathrm{p}=0.02)$. Gender, age, marital status, the person living with, cancer types and duration after diagnosis had no statistical significance. 
Table 3. Analysis showing the Socio-Demographic Characteristics Associated with Anxiety and Depression $(n=96)$

\begin{tabular}{|c|c|c|c|c|c|c|}
\hline Variables & $\begin{array}{r}\text { No Anxiety } \\
n\end{array}$ & $\begin{array}{l}\text { Anxiety } \\
(\%)\end{array}$ & $\mathrm{p}$ & $\begin{array}{r}\text { No depression } \\
\mathrm{n}(\%\end{array}$ & Depression & $\mathrm{p}$ \\
\hline Gender & & & 0.7 & & & 0.6 \\
\hline Male & $20(50.0)$ & $20(50.0)$ & & $14(35.0)$ & $26(65.0)$ & \\
\hline Female & $26(46.4)$ & $30(43.6)$ & & $17(30.4)$ & $39(69.6)$ & \\
\hline Age (years) & & & 0.1 & & & 0.4 \\
\hline $18-35$ & $8(72.7)$ & $3(27.3)$ & & $5(45.5)$ & $6(54.5)$ & \\
\hline $36-43$ & $6(37.5)$ & $10(62.5)$ & & $3(18.8)$ & 13(81.3) & \\
\hline $44-61$ & $23(53.5)$ & $20(46.5)$ & & $17(39.5)$ & $26(60.5)$ & \\
\hline $62-89$ & $9(34.6)$ & $17(65.4)$ & & $6(23.1)$ & $20(76.9)$ & \\
\hline Marital status & & & 0.1 & & & 0.1 \\
\hline Single & $4(80.0)$ & $1(20.0)$ & & $3(60.0)$ & $2(40.0)$ & \\
\hline Married & $35(50.0)$ & $35(50.0)$ & & $23(32.9)$ & $47(67.1)$ & \\
\hline Cohabit & $1(100)$ & $0(0)$ & & $1(100)$ & $0(0)$ & \\
\hline Separated & $3(50.0)$ & $3(50.0)$ & & $0(0)$ & $6(100)$ & \\
\hline Widow & $3(21.4)$ & $11(78.6)$ & & $4(28.6)$ & 10(71.4) & \\
\hline Person living with & & & 0.8 & & & 0.1 \\
\hline Family & $41(48.8)$ & $43(51.2)$ & & $30(35.7)$ & $54(64.3)$ & \\
\hline Friends & $2(50.0)$ & $2(50.0)$ & & $1(25.0)$ & $3(75.0)$ & \\
\hline Living alone & $3(37.5)$ & $5(62.5)$ & & $0(0)$ & $8(100)$ & \\
\hline Employment status & & & 0.02 & & & 0.9 \\
\hline Not employed & $7(26.9)$ & $19(73.1)$ & & $7(26.9)$ & 19(73.1) & \\
\hline Employed & $27(62.8)$ & $16(37.2)$ & & $16(37.2)$ & $27(62.8)$ & \\
\hline Retired & $5(55.6)$ & $4(44.4)$ & & $3(33.3)$ & $6(66.7)$ & \\
\hline Disabled by cancer & $7(39.9)$ & $11(61.1)$ & & $5(27.8)$ & $13(72.2)$ & \\
\hline Health insurance & & & 0.1 & & & 0.7 \\
\hline Public & $40(45.5)$ & $48(54.5)$ & & $29(33.0)$ & $59(67.0)$ & \\
\hline $\begin{array}{l}\text { Private } \\
\text { History of mental }\end{array}$ & $6(75.0)$ & $2(25.0)$ & & $2(25.0)$ & $6(75.0)$ & \\
\hline $\begin{array}{l}\text { disorder } \\
\text { No }\end{array}$ & $43(47.3)$ & $48(52.7)$ & & $31(34.1)$ & $60(65.9)$ & \\
\hline Yes & $3(60.0)$ & $2(40.0)$ & & $0(0)$ & $5(100)$ & \\
\hline
\end{tabular}

A significant association with found between anxiety and cancer stage $(\mathrm{p}=0.02)$, weight loss $(\mathrm{p}=0.00)$, fatigue $(\mathrm{p}=0.01)$ and depression $(\mathrm{p}=0.02)($ table 4$)$. A significant association was also found between depression and weight loss $(\mathrm{p}=0.02)$, pain $(\mathrm{p}=0.03)$, fatigue $(\mathrm{p}=0.02)$, cancer treatment $(\mathrm{p}=0.04)$ and anxiety $(\mathrm{p}=0.02)$. 
Table 4. Analysis showing Clinical and Cancer Factors Associated with Anxiety and Depression $(\mathrm{n}=96)$

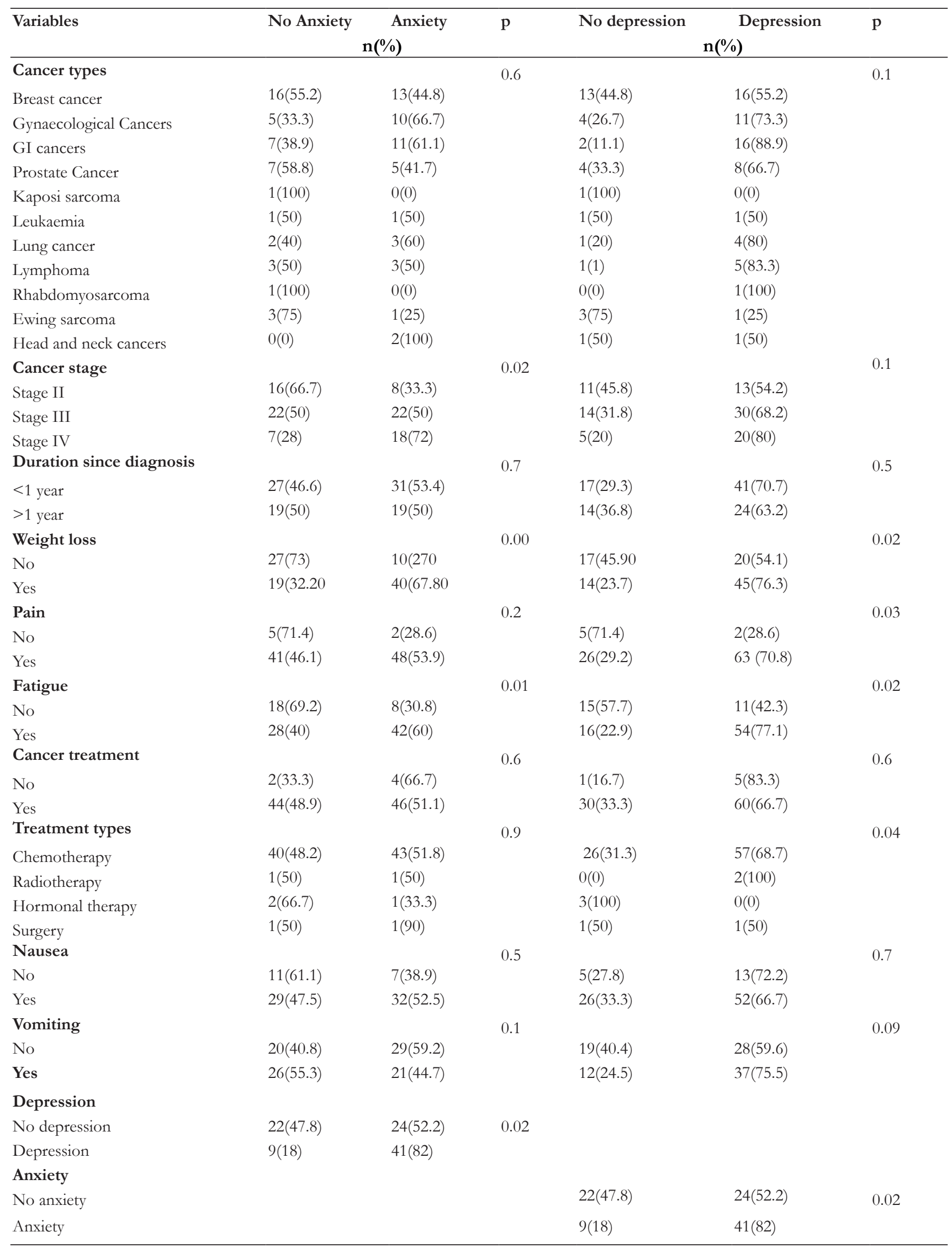




\section{Discussion}

The current study results revealed that the majority of participants were female $(58.3 \%)$, married $(73 \%)$, with a mean age of 52 years. This sample is similar to a study conducted in Iran where the female occupied $52 \%$ of all participants, and the majority were married.[21]

\section{Prevalence of anxiety and depression among cancer patients}

The current study used a cut-off point of $\geq 8$ of the HADS instrument, which Zigmond Snaith recommended to identify mild and symptomatic anxiety or depression cases in research.[19] The results revealed that the depression prevalence was higher than anxiety, as over two-thirds had depression (67.7\%), and only half had anxiety $(52.1 \%)$. These findings were similar to three studies: in China, the depression was a more significant psychological disorder among cancer patients than anxiety; [22] in Ethiopia the depression rate was $58.44 \%$, higher than the anxiety rate of $51 \%$; [23] and in Iran, the depression rate was $32 \%$ and anxiety $26.7 \%$.[21]

In contrast, two other studies used the HADS instrument and reported higher anxiety prevalence and lower depression levels among cancer patients. A Norwegian study indicated anxiety of $30 \%$ and a depression rate of $24.1 \%$, [24] and in Nepal, the anxiety rate was $40.0 \%$, and depression $28.0 \%$.[25]

Studies from Africa are limited, though what is published indicates a lower prevalence of anxiety and depression compared to the current study. In Nigeria, a study conducted among cancer patients attending a radiotherapy clinic revealed that $31.6 \%$ experienced different levels of depression, while $36.9 \%$ had varying levels of anxiety.

\section{Socio-demographic characteristics associated with anxiety and depression}

There was a significant relationship between employment status and anxiety $(\mathrm{p}=0.02)$. Similarly, a study conducted in China demonstrated that performance status influenced the development of depression and anxiety among cancer patients.[26] There were significant relationships between anxiety and depression, and older cancer patients in Nigeria,[10] Iran,[11] and China.[13]

In contrast, two other sociodemographic variables that were not associated with our study were significant in other studies. In Ethiopia[28] there was an association with gender, and others studies indicated educational level with anxiety and depression. [12,13]

\section{Clinical and cancer factors associated with anxiety and depression}

The results showed that weight loss and fatigue were associated with anxiety and depression, whereas fatigue $(\mathrm{p}=0.02)$ was associated with only depression. The previous studies reported that cancer symptoms, such as constant pain and change in body image, had an impact on the development of depression. The pain was associated with depression among cancer patients in China,[14] Oncology, and Radiotherapy Institute [NORI]. Patients and Methods. 300 patients were interviewed from both the outpatient and inpatient department using The Aga Khan University Anxiety and Depression Scale (AKUADS) and a significant problem in a study in LMIC where cancer patients were four times more likely to suffer from a major depressive disorder.[22]

Cancer stage was significantly associated with anxiety, and these results are similar to studies conducted in Indonesia,[29] and Portugal.[30] The current study revealed that depression had a significant association with treatment type, especially in cancer patients receiving chemotherapy $(68.7 \%)$, similar to another study.[21] Both anxiety and depression were considered comorbidities in the participants, which concurs with other studies.[27,31]

\section{Limitations}

The current study has limitations. We only used one study site, so the results cannot be generalised to all patients with cancer treated in Rwanda. A small sample size limited the power to predict associations between some variables. The study population consisted of patients undergoing curative and palliative care, yet their emotional state is likely to be significantly different. Since our study population was 100\% patients with cancer, we cannot compare some situations to the general population, such as employment status.

\section{Recommendations}

Hospitals need to develop policies and guidelines to integrate an anxiety and depression assessment into cancer care in Rwanda, with support from the University of Rwanda MScN faculty (Oncology speciality) and Ministry of Health. The presence of depression and anxiety disorders and its associated factors among cancer patients behoves health policymakers and hospitals to put in place specialised cancer subunits with a focus on psycho-oncology. A future study could include a larger sample size at both urban and rural locations, and a comparison between curative and palliative care patients.

\section{Conclusion}

The HADS instrument was an efficient screening tool for measuring anxiety and depression in the study population. The cross-sectional study findings indicated a high prevalence of anxiety and depression. All healthcare providers caring for cancer patients, 
including nurses and midwives, must focus not only on the physical parts of cancer care but also psychosocial and spiritual components. Information on how to provide comprehensive care to cancer patients should begin in educational programs at the university and continue in clinical sites.

\section{Authors' contributions}

All authors have contributed to the final version of the paper.

\section{Acknowledgements}

We are grateful to Dr Geldine Chironda and Rebecca White for the scientific assistance during this research and Dr Pamela Meharry for support with this publication by conducting the series of writing retreats at the University of Rwanda.

This article is published open access under the Creative Commons Attribution-NonCommercial NoDerivatives (CC BY-NC-ND 4.0). People can copy and redistribute the article only for noncommercial purposes and as long as they give appropriate credit to the authors. They cannot distribute any modified material obtained by remixing, transforming or building upon this article. See https:// creativecommons.org/licenses/by-nc-nd/4.0/

\section{References}

1. Pitman A, Suleman S, Hyde N, Hodgkiss A. Clinical updates Depression and anxiety in patients with cancer. BMJ-UK [nternet]. 2017;1-11. Available from: https://pdfs.semanticscholar.org/ca5c/17a 7230907477a2c310bf0e760c957bfbd9d.pdf

2. American Cancer Society. Anxiety, Fear, and Depression. 2016; Available from: http:// www.cancer.org/acs/groups/cid/documents/ webcontent/002816-pdf.pdf

3. Guan N, NZ Z. Prevalence of Depression in Cancer Patients: A Review on the Comparison Between Different Regions. Malaysian J Psychiatry Ejournal [Internet]. 2014;23. Available from: http://www.mjpsychiatry.org/index.php/mip/ article/view/332

4. Transforming cancer services team for london. Psychological support for people living with cancer Commissioning guidance for cancer care in London. London cancer alliance [Internet]. 2015; Available from: http://www.londonscn.nhs. uk/wp-content/uploads/2015/06/mh-cancercommissioning-guide-062015.pdf

5. Andersen BL, DeRubeis RJ, Berman BS, Gruman J, Champion VL, Massie MJ, et al. Screening, assessment, and care of anxiety and depressive symptoms in adults with cancer: An American Society of Clinical Oncology guideline adaptation. J Clin Oncol. 2014;32:1605-19.
6. Torre L, Rebecca Siegel AJ. Global Cancer Facts \& Figures 3rd Edition. Am Cancer Soc [Internet]. 2015;1-64. Available from: http://www.ncbi.nlm. nih.gov/pubmed/22019360

7. Andersen BL, Rowland JH, Somerfield MR. Screening, Assessment, and Care of Anxiety and Depressive Symptoms in Adults With Cancer: An American Society of Clinical Oncology Guideline Adaptation. J Oncol Pract [Internet]. 2015;11:1334. Available from: http://www.ncbi.nlm.nih.gov/ pubmed/25515721\%5Cnhttp://jop.ascopubs. org/cgi/doi/10.1200/JOP.2014.002311

8. Grassi L, Spiegel D, Riba M. Advancing psychosocial care in cancer patients [ version 1; referees : 3 approved ] Referee Status : 2017;6.

9. Park P. Butaro Cancer Centerhttp://www.imb.rw/ cancer-care.

10. Smith HR. Depression in cancer patients : Pathogenesis, implications and treatment ( Review ). 2015;1509-14.

11. Linden W, Vodermaier A, Mackenzie R, Greig D. Anxiety and depression after cancer diagnosis: Prevalence rates by cancer type, gender, and age 2 . J Affect Disord [Internet]. Elsevier B.V.; 2012;141:343-51. Available from: http://dx.doi. org/10.1016/j.jad.2012.03.025

12. Stafford L, Judd F, Gibson P, Komiti A, Mann GB, Quinn M. Anxiety and depression symptoms in the 2years following diagnosis of breast or gynaecologic cancer: prevalence, course and determinants of outcome. Support Care Cancer. 2015;23:2215-24.

13. Asuzu C, Adenipekun A. Correlates of depression and anxiety among the cancer patients in the radiotherapy clinic in Uch, IBADAN, NIGERIA. African J Psychol study Soc issues. 2015;18:11122.

14. Khalil A, Faheem M, Fahim A, Innocent H, Mansoor Z, Rizvi S, et al. Prevalence of Depression and Anxiety amongst Cancer Patients in a Hospital Setting: A Cross-Sectional Study. PsychiatryJournal. Hindawi Publishing Corporation; 2016;2016.

15. Alacacioglu A, Tarhan O, Alacacioglu I, Dirican A, Yilmaz U. Depression and anxiety in cancer patients and their relatives. JBUON. 2013;18:767-74.

16. National comprehensive care network(NCCN). Distress management. 2017.

17. Rwanda Biomedical center. Rwanda marks World Cancer Day. 2016;

18. National council of OsthepathicResearch. The 
Hospital Anxiety and Dpression Scale (HADS). 2011;150:7-8.

19. National counsil of OsthepathicResearch. The Hospital Anxiety and Depression Scale (HADS). 2008;150:7-8.

20. Olssøn I, Mykletun A, Dahl AA. The hospital anxiety and depression rating scale: A crosssectional study of psychometrics and case finding abilities in general practice. BMC Psychiatry. 2005;5:1-7.

21. Nikbakhsh N, Moudi S, Abbasian S, Khafri S. Prevalence of depression and anxiety among cancer patients. Casp J Intern Med 2014; 5(3) 167 170. 2014;3-6.

22. Alemayehu M, Deyessa N, Medihin G, Fekadu A. A descriptive analysis of depression and pain complaints among patients with cancer in a low income country. 2018;1-14.

23. Berihun F, Haile S, Abawa M, Mulatie M, Shimeka A. Prevalence and correlates of anxiety and depression among cancer patients in the University of Gondar Comprehensive Specialized Hospital, Northwest Ethiopia. 2017;3:42-8.

24. Cardoso G, Graca J, Klut C, Trancas B, Papoila A, Cardoso $\mathrm{G}$, et al. Depression and anxiety symptoms following cancer diagnosis : a cross-sectional study. 2016;8506.

25. Thapa P, Rawal N, Bista Y. A study of depression and anxiety in cancer patients. 2010;12:171-5.

26. Hong JS, Tian J. Prevalence of anxiety and depression and their risk factors in Chinese cancer patients. Support Care Cancer [Internet]. 2014;22:453-9. Available from: http://www.ncbi. nlm.nih.gov/pubmed/24091720

27. Linden W, Vodermaier A, MacKenzie R, Greig D. Anxiety and depression after cancer diagnosis: Prevalence rates by cancer type, gender, and age. J Affect Disord [Internet]. Elsevier B.V.; 2012;141:343-51. Available from: http://dx.doi. org/10.1016/j.jad.2012.03.025

28. Berihun F, Haile S, Abawa M, Mulatie M, Shimeka A. Archives of Depression and Anxiety Prevalence and correlates of anxiety and depression among cancer patients in the University of Gondar Comprehensive Specialized Hospital , Northwest Ethiopia. 2017;3:42-8.

29. Johanes C, Monoarfa RA, Ismail RI, Umbas R. Anxiety level of early- and late-stage prostate cancer patients. 2013;1:177-82.

30. Cardoso G, Graca J, Klut C, Trancas B, Papoila A. Depression and anxiety symptoms following cancer diagnosis: a cross-sectional study. Psychol Health Med. 2015;8506:1-9.

31. Sharma A, Zhang J. Depression and its predictors among breast cancer patients in Nepal. ASEAN J Psychiatry [Internet]. 2015;16:106-15. Available from: http://search. proquest.com/docview/1676369356?accounti $\mathrm{d}=14744 \% 5$ Cnhttp: / / fama.us.es/search*spi/ i?SEARCH $=22317805 \% 5 \mathrm{Cnhttp}: / /$ pibserver. us.es/gtb/usuario_acceso.php?centro=\$USEG\&c entro $=\$ U S E G \& d=1$ 